\title{
BASES METOdOLÓGICAS PARA A ASSISTÊNCIA DE ENFERMAGEM EM SAÚDE COLETIVA, FUNDAMENTADAS NO MATERIALISMO HISTÓRICO E DIALÉTICO*
}

Vilma Machado de Queiroz** Emiko Yoshikawa Egry**

\begin{abstract}
RESUMO - As autoras propõem uma metodologia de assistência de enfermagem em saúde coletiva, fundamentada no materialismo histórico, partindo da concepção e visão de mundo nesta ótica, da recolocação de pressupostos e das leis da dialética materialista. Neste referencial aceita-se que o processo saúde-doença é determinado socialmente, em uma dada realidade objetiva, e que esta realidade deve ser abordada em três dimensões, a saber: "dimensão estrutural", formada pelos processos de desenvolvimento da capacidade produtiva e de relações sociais; a "dimensão particular", formada pelos processos de reprodução social e a "dimensão singular", formada pelos indivíduos e suas famílias. A metodologia de assistência de enfermagem em saúde coletiva ora proposta é desenvolvida nas seguintes fases: a) captação da realidade objetiva; b) interpretação da realidade objetiva; c) construção dó projeto de intervenção na realidade objetiva; d) intervenção na realidade objetiva; e) reinterpretação da realidade objetiva. Em cada uma dessas fases, as três dimensões da realidade objetiva, acima mencionadas, são consideradas de forma simultânea.
\end{abstract}

ABSTRACT - The authors suggest a nursing assistance methodology in public health, ba se on historical-dialectical-materialism, starting from the conception and from world view, according to this referential, and from the laws of the materialist dialectic. In this referential it is accepted the health-illness process when socially stated for a giving objective reality, and taking in account this reality must be approached in three dimensions, as follows: "the structural dimension", formed by the development processes of the productive ability and of the social relations: "the particular dimension", formed by the social reproduction processes; and "the singular dimension" formed by the individuals and their families. The proposed nursing assistence methodology in public health is developed in following steps: a) obtainning the objective reality; b) interpretaitting the objective reality; c) elaborating a project for intervenning in the objective reality; d) intervenning in the objective reality; e) reinterpretatting the objective reality. In each of this steps, above mencionned, three dimensions must be considered simultaneously.

\section{INTRODUÇÃO}

O materialismo histórico e dialético, como dundamentação filosófica vem sendo utilizado por diferentes autores para o estudo, análise e interpretação da enfermagem brasileira nos últimos anos, como os de ALMEIDA \& ROCHA (1986), NAKAMAE (1986), SILVA (1986). Este referencial diverge radicalmente de outro adotado por muitos anos na prática da enfermagem, mesmo que não claramente explicitado, e que tem suas bases no referencial idealista.

$\mathrm{Na}$ concepção materialista histórica e dialética, considera-se que o processo saúde-doença é socialmente determinado, pois as transformações sociais ocorridas em um determinado momento histórico, geram transformações na saúde, tanto na sua estrutura como no sistema de saúde.

Nesta concepção, ainda, a sociedade é entendida

\footnotetext{
* Prêmio Isaura Barbosa Lima - 10. lugar

** Professor Assistente Doutor do Departamento de Enfermagem em Saúde Coletiva da Escola de Enfermagem da USP.
} 
como a "totalidade das relações de produção e das forças produtivas, que formam sua estrutura econõmica, a qual serve de base real onde se ergue uma superestrutura jurídica e política, e à qual correspondem determinadas formas de consciência social e onde se desenvolve o processo de vida social" (HAHN \& KOSING, 1983).

Entende-se por relações de produção, "as relações que os homens estabelecem entre sí na produção e reprodução da sua vida material, em virtude de a produção se realizar sempre de modo social, na ação conjunta de muitas pessoas; abrangema propriedade dos meios de produção, bem como a troca e a repartição das atividades necessárias ou dos bens produzidos (HAHN \& KOSING, 1983).

Por forças produtivas compreendem-se "todas as forças que são necessárias para produzir bens materiais para a satisfação de necessidades humanas: forças físicas e intelectuais do próprio homem, forças e materiais da natureza, quer na forma não trabalhada de matérias-primas, energia hidráulica e semelhantes, quer na forma já trabalhada de meios de produção (portanto, máquinas, instrumentos, aparelhos, técnica, aplicação de conhecimentos científicos), mas também a direção da produção, a sua tecnologia e organização. As relações de produção e as forças produtivas formam, em conjunto, o modo de produção (HAHN \& KOSING, 1983).

A superestrutura jurídica e política se refere ao "pluriforme sistema do Estado e seus órgãos: órgãos legislativos e administrativos, exército, polícia, justiça, partidos políticos e outras organizações sociais, instituições culturais tais como o sistema educativo, imprensa, rádio e televisão, instituições artísticas, igreja ou outras instituições de ação religiosa e outras mais" (HAHN \& KOSING, 1983).

As formas de consciência social são "as idéias, concepções, convicções, teorias sobre a vida social, ideologias, normas jurídicas, regras e mandamentos morais, concepções e expressões artísticas, a religião, a visão do mundo; estas formas de consciência social estão em estreita ação com a "superestrutura jurídica e política" (HAHN \& KOSING, 1983, p. 139).

Por processo de vida social, entende-se "a organização das pessoas nos mais diversos agrupamentos sociais, sobretudo e em primeira linha, naturalmente, em classes, mas também em determinados coletivos, em população urbana e rural, em profissões ou outros setores de atividade, em famílias ou outras unidades sociais assentes numa ascendência e origem comuns ou no parentesco" (HAHN \& KOSING, 1983, p. 139).

O Homem é, portanto, visualizado como ser social e que se insere enquanto classe social (BRONFMAN \& TUIRAN) na sociedade através do sistema produtivo, ou seja, do trabalho.

A dinãmica da relação entre os modos de produção, a inserção das classes no sistema produtivo, em um dado momento histórico, é que determina a saúde enquanto estrutura e enquanto sistema.

Nesta forma materialista histórica e dialética de ver o mundo, os homens são vistos dentro de uma ótica coletiva, sempre inseridos em uma classe social, que é o reflexo de sua inserção no sistema de produção e que é ele que determina a saúde.

0 enfoque da saúde do ponto de vista do coletivo e não do individual justifica-se em razão de que a dinãmica social das classes é que determina a saúde, considerando a saúde, o efeito, e não a causa e com isso, negando-se que o somatório dos fatores individuais da saúde irão dar um retorno dinãmico de sua estrutura.

0 referencial materialista histórico e dialético pressupõe à sua compreensão, uma tomada da realidade objetiva, ou seja, do concreto, consideradas as transformações históricas socialmente determinadas, e que estas transformações ocorrem pela explicitação e superação das contradições que emergem. Contrapõemse a ele, a universabilidade e a imutabilidade, que significam que os fenõmenos ocorrem e explicam-se para todas as sociedades em todos os tempos de forma "uniforme" e "predizível", negando com isto as diferenciações determinadas pela inserção do homem em classes sociais antagõnicas.

Com isto, significa que a metodologia de assistência de enfermagem dentro da concepção materialista histórica e dialética ora proposta, sofrerá transformações no tempo e no espaço, transformações estas, oriundas daquelas que dinamicamente movem a sociedade brasileira e portanto, também a prática da enfermagem. Pressupõem assim que a enfermagem e a própria assistência não se caracterizam como meros objetos das transformações sociais, mas que elas serão também as que irão transformá-la. Isto é, a enfermagem em sua prática sofre as transformações não como simples objeto, mas sim como sujeito de sua transformação - ao mesmo tempo que as transformaçẽos da sociedade impõem mudanças na prática profissional, as transformações da prática profissional levam à mudanças sociais.

Para que a prática profissional resulte em intervenções conscientes de transformações sociais, é necessário que o profissional e o cliente se assumam, enquanto prática de assistência, como "sujeitos" de um mesmo processo na formulação e busca de horizontes concretos de saúde; isto é, no desenvolvimento de trabalho conjunto, sistematizado e dinãmico de captar e interpretar a realidade de saúde e de enfermagem de uma coletividade, dentro de um contexto social historicamente determinado, de interferir nesta realidade e, nessa intervenção, ir reinterpretando a realidade e novamente intervindo sobre ela. Para que isto ocorra de forma concreta, é necessário visualizar-se um horizonte, que neste referencial é distinto da utopia idealista, pois ele é construído na medida que se caminha, ao mesmo tempo é móvel porque ao atingi-lo já estarão sendo construídos novos horizontes; além disso, tal ho- 
rizonte não é único para toda a coletividade, contrapondo-se novamente à universalidade e ao ideal abstrato que é construído por grupos hegemõnicos, uma vez que no referencial adotado esta construção é feita pelos sujeitos participantes do processo.

\section{BASES CONCEITUAIS QUE FUNDAMENTAM A ASSISTÊNCIA DE ENFERMAGEM DENTRO DO REFERENCIAL MATERIALISTA HISTÓRICO E DIALÉTICO.}

A adoção do referencial materialista histórico e dialético, obriga necessariamente a recolocação de conceitos já amplamente utilizados em enfermagem e em saúde, e que por apresentarem bases dentro da concepção idealista, impedem a utilização imediata em outro referencial.

A seguir serão resumidamente abordados conceitos dos quais dependem a compreensão do próprio desenvolvimento da metodologia proposta.

Por processo saúde-doença entende-se a resposta dinãmica que classes sociais manif estam de forma diferenciada, de acordo com sua inserção no sistema de produção, frente aos determinantes sociais, resposta esta, dada pelas características de riscos ou potencialidades que são reflexos do processo biológico de desgaste (LAUREL, 1983; BREILH \& GRANDA, 1986, p. 40).

Como a qualidade de vida de cada classe social é diferente, em nossa sociedade, é diferente também a sua exposição a processos de risco e 0 acesso a processos benéficos ou potencialidades de saúde (BREILH \& GRANDA, 1986, p. 40).

Isto posto, a assistência à saúde coletiva significa a forma de interferência consciente (sistematizada, planejada e dinãmica) no processo saúde-doença, de uma dada coletividade, consideradas as distinções das classes sociais; realizada pelo conjunto dos prof issionais de saúde com a coletividade, objetivando o desenvolvimento da consciência crítica de cada classe social em relação a sua realidade de saúde, tornando-se portanto sujeito de suas próprias transformações.

0 desenvolvimento desta consciência crítica deve iniciar-se com a reflexão crítica da prática dessa assistência. Tal "reflexão crítica consiste na busca e análise de informações sobre a realidade profissional e de saúde, inserindo esta busca e análise no contexto das relações sociais da coletividade e também na identificação de pontos vulneráveis e de momentos e formas de intervenção no curso histórico da evolução dessa realidade" (LIMA et alii, 1979).

A assistência à saúde coletiva, com este significado é um horizonte que se visualiza hoje, e ao caminhar para este horizonte, a enf ermagem deve ser considerada como sendo um corpo de conhecimentos e habilidades específicos, construídos e reproduzidos em decorrência da divisão social do trabalho na área de saú- de, e com isto (corpo de conhecimentos e habilidades) intervêm no processo saúde-doença, cuja forma de intervenção será a seguir descrita na metodologia de assitência de enfermagem.

\section{METODOLOGIA DE ASSISTÊNCIA DE ENFERMAGEM}

A metodologia de assistência de enfermagem será descrita abordando o conceito de metodologia, as etapas e o desenvolvimento do método.

\subsection{Conceito}

A metodologia de assistência de enfermagem é a sistematização dinâmica de captar e interpretar a realidade de saúde e de enfermagem de uma coletividade, dentro de um contexto social historicamente determinado, de intervir nessa realidade e nessa intervenção ir reinterpretando a realidade e novamente intervindo sobre ela.

A realidade referida é a realidade objetiva que é aquela que tem como propriedade "de existir independentemente e fora da consciência humana" (HAHN \& ROSING, 1983, p.50). A aproximação da realidade objetiva, para o desenvolvimento da assistência de enfermagem, deve ser realizada tendo em vista o seu desdobramento em três dimensões: a dimensão estrutural, que é formada pelos processos de desenvolvimento da capacidade produtiva e de desenvolvimento das relaçōes de produção, da formação econõmica social e das formas político-ideológicas derivadas; a dimensão particular, que é formada pelos processos de reprodução social, perfis epidemiológicos de classe integrados pelo perfil reprodutivo de classe e perfil de saúde-doença, e formas especiais de prática e ideologia em saúde; e a dimensão singular formada pelos processos que em última instância leva a adoecer e a morrer, ou ao contrário, a desenvolver o "nexo biopsíquico", dados pelo seu "funcionamento", consumotrabalho individual e pelas formas de participaçâo individual de organização e consciência (BREILH \& GRANDA, 1986, p. 57).

A aproximação da realidade objetiva pelas três dimensões mencionadas é necessária para que o sujeito das ações de enfermagem tome consciência de sí próprio, de seu papel dentro da classe social e dentro do sistema social; desta forma a intervenção realizada nâo será somente no seu processo singular de saúde e doença, como indivíduo e família, mas também no processo saúde-doença de sua classe social e da própria sociedade em que vive.

\subsection{Etapas do método}

A descrição do método será feita em etapas seqüenciais, apresentadas desta forma por ser mais didático, 
porém sem a conotação de que as mesmas são estanques, ressaltando que ao longo do desenvolvimento, elas se interpenetram.

Este método pode ser aplicado em diferentes níveis ou focos de atenção individual (por exemplo, consulta de enfermagem), familiar (por exemplo, na assistência de enfermagem à família realizada no domicílio), pequenos grupos e coletividade.

\section{1. etapa: Captação da realidade objetiva}

A captação da realidade objetiva consiste em conhecer tal realidade nas três dimensões e dentro delas os grupos temáticos a serem abordados:

Grupo temático referente à dimensão estrutural

- o sistema de saúde vigente como um todo e a forma de vinculação do sujeito à ele;

- a atuação das instituições de saúde na problemática de saúde expectativas e experiências vividas em relação às respostas esperadas destas instituições;

- dinâmica e a historicidade das transformações ocorridas no sistema de saúde.

Grupo temático referente à dimensão particular

- a dinâmica e a historicidade do processo saúdedoença dentro de diferentes classes sociais, destacando a inserção do sujeito em dada classe social;

- dinâmica e historicidade de movimentos populares e sua vinculação à eles.

Grupo temático referente à dimensâo singular

- dinâmica e historicidade de sobrevivência e/ou aperfeiçoamento da saúde, relacionados a:

- processo saúde-doença: problemas e/ou questões de saúde; qualidade; dinamicidade; interferência em outros níveis;

- ambiente físico: espaço/uso; propriedade; saneamento; localização x recursos; população; aparelhamento urbano; mobilidade;

- alimentação: acesso; qualidade; quantidade; produção;

- transporte: acesso; tempo gasto; número de trocas; propriedade;

- educação: acesso; educação formal/não formal; fontes de obtenção de temática reflexiva; qualidade; - trabalho: ambiente físico; vinculação; dinâmica de vinculação; trabalho remunerado/não remunerado; salário/renda; utilização/distribuição da renda;

- relações familiares e/ou grupais: qualidade; opor tunidade; coesão; vida reprodutiva;

- prazer: qualidade (realizações reflexivas ou reiterativas); quantidade; participação individual ou grupal;

- corpo biopsíquico: domínio; desgaste físico e emocional; sensações (respostas à estímulos); funcionamento do corpo (cárdio-vascular, respiratório, gastro-intestinal, locomotor, sentidos, genitourinário, cutâneo-mucosa).

\section{$2^{a}$ etapa: Interpretação da realidade objetiva}

A interpretação da realidade objetiva, iniciada a sua captação na primeira etapa, é realizada pela explicitação das contradições existentes nas três dimensões e seus grupos temáticos. Deve ser descoberto para cada tema e também no seu conteúdo total, os polos contrários, que compõe na luta entre eles, a unidade e luta dos contrários. Esta etapa, realizada em conjunto profissional/cliente, é tanto mais complexa e difícil quanto maior for a consciência ingênua do sujeito, ou seja, a alienação dele, que se caracteriza, de acordo com LANE (1984, p.42) "pela atribuição da 'naturalidade', aos fatos sociais; esta inversão do humano, do social, do histórico como manif estação da natureza, faz com que todo o conhecimento seja avaliado em termos de verdadeiro ou falso e de universal; neste processo a 'consciência' é reificada, negando-se como processo..."

\section{3. etapa: Construção do projeto de intervenção na rea-} lidade objetiva

À medida em que se capta a realidade objetiva, e explicitam-se as contradições existentes na fase de interpretação da realidade objetiva pertinentes à saúde, deve ser elaborado um projeto de intervenção nesta realidade, tanto na dimensão singular, particular, como na estrutural. Tal projeto de intervenção deve ser construído em conjunto profissional e o sujeito da assistência, permitindo, desta forma, a tomada de consciência e a reflexão crítica da realidade objetiva em relação à saúde.

Ao construir o projeto de intervenção na realidade objetiva, as contradições explicitadas na fase anterior devem ser submetidas ao exame da vulnerabilidade de conteúdo, isto é, da possibilidade real de romper e interferir nesta realidade, pelos conhecimentos e avanços existentes; da vulnerabilidade espacial que é dada pela oportunidade ou época em que poderá haver o ponto de ruptura, ou seja, a ultrapassagem da contradição exposta; da vulnerabilidade da forma, isto é, as formas ou alternativas de proposição que podem causar o rompimento.

0 projeto de intervenção deve conter objetivos de alcance comum (profissional/sujeito) estabelecendo, também, em conjunto, as épocas de alcance dos mesmos. Importante frisar que estes não são imutáveis, pois, à medida em que eles (objetivos) estão sendo traçados, novos temas da realidade objetiva podem estar sendo captados e interpretados, o que deve modificar substancialmente a proposição inicial. Portanto, eles são contínuos e refeitos em todos os momentos, o que não significa que os mesmos não devam ser claramente expostos, uma vez que a própria mudança de rumos é decorrente da reinterpretação continuada e revela por si só o movimento de consciência. 


\section{4. etapa: Intervenção na realidade objetiva}

Nesta etapa, em continuidade dinâmica com as anteriores, são postos em prática os objetivos propostos. Esta prática não se limita à dimensão singular, onde muitas vezes é iniciado o processo, mas deve abranger simultaneamente todas as três dimensões na intervenção de temas específicos, visando a superação das contradições explicitadas.

\section{5. etapa: Reinterpretação da realidade objetiva}

Nesta etapa deve haver uma releitura da realidade objetiva, frente às transformações ocorridas ou não, diante das intervenções realizadas nas três dimensões e em seus desdobramentos temáticos. Devem ser recolocados e analisados os impactos, as dificuldades surgidas no processo de superação das contradições, bem como o redimensionamento do horizonte (ou objetivos) anteriormente posto e a projeção de novas proposições.

\subsection{Desenvolvimento do método}

O desenvolvimento deste método de assistência de enfermagem por ser dentro do referencial materialista histórico e dialético, baseia-se nas leis fundamentais da dialética materialista que explicam o decurso geral e o mecanismo interno da ação deste desenvolvimento, descrevendo, ainda, a orientação dos processos do mesmo.

As leis fundamentais da dialética materialista abrangem conexões do próprio mundo material, conexões que existem fora da consciência humana e independente dela (HAHN \& ROSING, 1983, p.66). São elas: a lei da unidade e luta dos contrários; lei da passagem de transformações quantitativas a novos estados qualitativos; a lei da negação da negação (CHEPTULIN, 1982).

A lei da unidade e da luta dos contrários já descrita na etapa de interpretação da realidade objetiva é utilizada nas demais etapas, pois, nela baseiam-se as transformações que nada mais são do que a explicitação dos polos contráros e a ultrapassagem que geram as transformações. As contradições são explicitadas passo a passo no decurso de toda a aplicação do método, buscando, além de sua explicitação, encontrar pontos vulneráveis para a provocação de mudanças.

A lei da passagem de quantidade para a qualidade, ocorre e explica as transformações que sucedem durante todas as fases do método, primeiro em forma de pequenas modificações como "reformas" da estrutura existente até que estas se juntancio transformem qualitativamente produzindo nova estrutura, que também, por sua vez contém e manifestam contradições que se iniciam com mudanças quantitativas.

Isto significa que no decorrer da assistência de enfermagem, as percepções, os comportamentos, as ati- tudes, as reflexões, terão primeiramente a característica de pequenas e contínuas questões que ao se tornarem quantitativamente significativas, rompem com a qualidade anterior e produzem uma nova.

Exemplo que se pode colocar é a compreensão por parte de determinados sujeitos, a respeito de que a doença é provocada por agentes externos sem nenhuma conexão com as dimensões particular e estrutural e mesmo com os demais sub-temas da dimensão singular - revela com isto que o sujeito é dotado de consciência ingênua de sua realidade objetiva. Ao perceber as conexões existentes da realidade objetiva e por ter conta de como estão imbricadas, produzem-se ações nível de transformações, como por exemplo a busca de determinadas formas diferentes de sua sobrevivência e/ou aperf eiçoamento de vida. Ao conectar com outros temas e ao evoluir a reflexão, tornando-se agora mais crítica, pode buscar outras formas de interpretar o processo saúde-doença e a relação com o trabalho, e com isto, a determinação de sua própria condição de vida. A ação gerada pela consciência reflexiva produz novas relações, e nesta produção há construção de uma nova qualidade.

A lei da negação da negação explica principalmente a etapa da realidade objetiva, onde já pelo desenvolvimento das etapas anteriores, a realidade objetiva foi "construída" e aproximada do consciente, e que houve tomada de decisão em como proceder a intervenção, sucedida da própria intervenção e que ao ser assim posto, ela organiza de forma diferenciada os dados da realidade objetiva, portanto, ao retomá-la, nega-a. Com isto no decorrer da assistência de enfermagem, ao produzir transformações é negada a realidade anterior, projetando novos horizontes que serão também negados em fase posterior.

Convém ressaltar que ao se negar e superar aspectos da realidade objetiva anterior, com a obtenção de uma nova qualidade, a qualidade anterior, com a obtenção de uma nova qualidade, a qualidade anterior é negada, suprimida, eliminada, "mas não é simplesmente aniquilada, não desaparece sem deixar marcas. Pelo c'ontrário, nesta negação preserva-se o anterior resultado positivo do desenvolvimento subseqüente" (HAHN \& ROSING, 1983, p.73).

Nota-se com isso que é preciso frisar a dinamicidade do método e a interpenetração das etapas, que o diferencia de modelos assistenciais utilizados até então, dentro da ideologia idealista, e que ao transcorrerem as etapas, as leis da dialética materialista deverão ser utilizadas para sua consecução, conforme pode ser visto no Quadro 1. Isto significa que as etapas a serem percorridas são contínuas e não se findam, em um mesmo momento de assistência de enfermagem; percorrer-se-ão infinitas vezes as mesmas, pois a cada passo novos horizontes são construídos e serão também alcançados ou modificados.

Ao revelar esta metodologia de forma total, e, por- 
tanto, bastante complexa em seu conteúdo de desenvolvimento e busca das verdades parciais, fica pairando a questão mais concreta de quais seriam esses dados da realidade objetiva com que se deve iniciar a captação, já que este total de dados não pode ser captado nem desenvolvido em uma única relação profissional/sujeito.

Os dados iniciais, devem ser aqueles que estão mais próximos do sujeito, mesmo que uma resolução mais "imediatista", mas, no "lidar" com este conteúdo temático, que lhe é mais próximo, e no desdobramento deste conteúdo mas três dimensões e sempre pela simultaneidade delas é que proporciona esta aproximação materialista e dialética. E, neste desdobramento, surgem, de um lado pela própria conexão, e de outro com a entrada dos conhecimentos específicos do profissional diante da visão sobre o processo saúde-doença, historicamente determinado, é que novos conteúdos temáticos virão à tona para novas intervenções.

Tanto as três dimensões e seus conteúdos temáticos, como as etapas, correm e percorrem a cada momento de encontro profissional/sujeito, prestada à coletividade (também em distintos focos como o de pequenos grupos, família e indivíduos), como também percorrem em todo o processo da assistência de enfermagem, tendo portanto objetivos ou horizontes iniciais, de curto prazo, propostos em um encontro, como também horizontes mais a prazo mediano e longo, propostos para serem atingidos no decorrer de um conjunto de encontros sistematizados e planejados.

\section{SÍNTESE}

A adoção do referencial materialista histórico e dialético e de suas leis, para fundamentar a metodologia de assistência de enfermagem, principia, para o profissional, pela mudança da visão de mundo, quando, aplicando-se a "lei da negação da negação", supera-se a visão idealista anterior, negando-se a assumir, e superando o papel que lhe é conferido pela classe dominante; papel este, de reprodutor de uma ideologia de saúde que privilegia esta classe em detrimento de outra, majoritária, que é dominada, espoliada e que serve, em última instância, de "objeto" do qual se deve reduzir tensões por meio de políticas de saúde. Essas políticas revelam nos seus discursos, conteúdos ideológicos que tentam encobrir as diferenciações de acesso e de condições de saúde de classes sociais, como por exemplo "extensão

QUADR() 1 - Esquema simplificado da proposição metodológica de assistência de enfermagem no referencial materialista históricoo e dialéti(o.).

\begin{tabular}{|c|c|c|c|}
\hline $\begin{array}{c}\text { DIMENSÕES } \\
\text { ETAPAS DO TRABALHO }\end{array}$ & DIMENSÃO ESTRUTURAL & DIMENSÃO PARTICULAR & DIMENSÃO SINGULAR \\
\hline $\begin{array}{l}\text { CONHECIMENTO DA } \\
\text { REALIDADE OBJETIVA }\end{array}$ & $\begin{array}{l}\text { - } \text { PROCESSO } \\
\text { PRODUTIVO } \\
\text { - PROCESSO JURÍDICO- } \\
\text { POLIITICO } \\
\text { - DINÂMICA NO } \\
\text { TEMPO }\end{array}$ & $\begin{array}{l}\text { - CLASSES SOCIAIS: } \\
\text { INSERÇÃO NO } \\
\text { SISTEMA PRODUTIVO }\end{array}$ & $\begin{array}{l}\text { - DIMENSÃO BIO- } \\
\text { PSÍQUICA DOS } \\
\text { ESTRATOS E } \\
\text { FRAĈ̃ES } \\
\text { - DINAMICA DE } \\
\text { MANUTENÇÃO DE } \\
\text { VIDA } \\
\text { - DINÂMICA DE } \\
\text { APERFEIÇOAMENTO } \\
\text { DE VIDA }\end{array}$ \\
\hline $\begin{array}{l}\text { INTERPRETAÇÃO DA } \\
\text { REALIDADE OBJETIVA }\end{array}$ & \multicolumn{3}{|c|}{ EXPLICITAÇÃO DAS CONTRADIÇÕES } \\
\hline $\begin{array}{l}\text { CONSTRUÇÃO DE } \\
\text { PROJETO DE } \\
\text { INTERVENÇÃO NA } \\
\text { REALIDADE OBJETIVA }\end{array}$ & \multicolumn{3}{|c|}{ PROJETO DE SUPERAÇÃO DAS CONTRADIÇÕES } \\
\hline $\begin{array}{l}\text { INTERVENÇÃO NA } \\
\text { REALIDADE OBJETIVA }\end{array}$ & \multicolumn{3}{|c|}{ SUPERAÇÃO DAS CONTRADIÇÕES } \\
\hline $\begin{array}{l}\text { REINTERPRETAÇÃO DA } \\
\text { REALIDADE OBJETIVA }\end{array}$ & \multicolumn{3}{|c|}{ NEGAÇÃO DA REALIDADE ANTERIOR } \\
\hline
\end{tabular}


de cobertura", "acesso universal", "desenvolvimento de tecnologia apropriada".

Esse referencial, ao ser adotado pelos profissionais, requer também a negação do reducionismo simplista do processo saúde-doença, superando o modelo unicausal da doença, que está sempre colocado fora do organismo agredido; superando, ainda, o modelo multicausal do processo saúde-doença, que se limitara a "descobrir fatores causais na produção de problemas fáceis de atacar, com medidas baratas e que permitam implementar medidas coletivas de controle" (BREILH \& GRANDA, 1986, p. 20). Esse modelo, portanto, não trata de chegar às verdadeiras causas do problema, mas sim, "de colocar uma cortina ideológica" que distorça a realidade, mas que permita, ao mesmo tempo, "obter resultados pragmáticos adequados". Esse "modelo não permite, portanto, buscar as verdadeiras causas do problema, (...) senão dar uma resposta "prática", cortando a cadeia causal mediante a supressão ou modificação de uma das variáveis intervenientes no aparecimento com o fim de conseguir diminuí-lo a níveis toleráveis, sem tocar as causas estruturais que podem 'desequilibrar' o sistema" (BREILH \& GRANDA, 1986 , p.20).

No referencial materialista histórico e dialético, deve-se ainda negar e superar o modelo do processo saúde-doença segundo a "tríade ecológica de Leavell e Clark", pois nele, "ignora-se a categoria social do Homem, transformando-o em um 'fator eminentemente biológico', que permite esconder as prof undas diferenças de classe que existem". Esse modelo permite simplesmente "restaurar as condições biológicas para que o homem, como força de trabalho, se mantenha no mercado". Ao se separar artificialmente o 'sujeito social' (fator homem) de sua produção, (...) se desvanece a origem social desses produtos". "Esta interpretação deformada permite propor medidas corretivas biológicoecológicas e em nenhum momento buscar transformações estruturais que atentem contra o equilíbrio do sistema (BREILH \& GRANDA, 1986, p. 21).

Ao se negar e superar as contradições do modelo hegemônico da sociedade e de saúde, deve-se reinterpretar a realidade objetiva à luz do referencial materialista histórico e dialético para captar que a "vida social", e o processo saúde-doença "como um de seus elementos, são parte do universo, que existe objetivamente como um conjunto de processos em ininterrupto desenvolvimento", considerando então, os "processos estruturais da sociedade que, por se acharem na base do desenvolvimento da coletividade, permitem explicar $o$ aparecimento de condições de vida particulares"; de considerar os "perfis de reprodução social (...) dos dif erentes grupos sócio-econômicos (classes sociais) com suas correspondentes potencialidades (...) de saúde e sobrevivência, assim como os riscos (...) de adoecer e morrer"; e de levar em consideração, também, "a compreensão integral dos fenômenos biológicos que configuram os padrões típicos de saúde-doença dos grupos e dos indivíduos que os compõem" (BREILH \& GRANDA, 1986, p.21).

0 profissional que adotar esse referencial materialista histórico e dialético deverá ainda superar o "idealismo" de que sua profissão teria a incumbência de educar e prestar assistência para "melhorar a saúde do povo", com receitas pré-determinadas, situando a problemática de saúde a nível individual e a sua resolução restrita à decisão do prof issional. Ao superar este idealismo, um novo horizonte, desta vez real e dinãmico deverá ser traçado. Neste horizonte, a sua atuação específica como profissional deverá ser um "meio" ou uma "forma" de compartilhar seu saber específico, juntamente com outros profissionais, no trabalho conjunto com o sujeito das ações (coletividade, grupos, famílias, indivíduos), visando a: captação e interpretação da realidade de saúde, dentro de um contexto social historicamente determinado; interferência nessa realidade e com isto ir reinterpretando a realidade e novamente intervindo sobre ela.

Esta metodologia de assistência de enfermagem possibilitará desfazer os mitos vigentes na enfermagem e na saúde como o do "messianismo" que confere não só poder como responsabilidade absolutos ao enfermeiro quando da sua assistência ao paciente; ou de "impotência profissional" ao não conseguir "sozinho" modificar as condições, ainda que singulares, de cada pessoa, todos eles origináros de uma postura idealista de prática profissional. Nesta prática é inevitável que surjam sentimentos de "culpa" ora responsabilizando a clientela, ora responsabilizando o profissional pela não "melhora das condições de saúde".

Ao contrário, neste referencial que fundamenta a assistência de enfermagem proposta neste trabalho, estas questões anteriores serão desmistificadas, superadas pela criação e produção conjunta de outras condições objetivas de vida e saúde, que consideram neles as três dimensões da realidade objetiva, ou seja a dimensão estrutural, a dimensão particular, a dimensão singular.

\section{REFERÊNCIAS BIBLIOGRÁFICAS}

1. ALMEIDA, M.C.P. de \& ROCHA, J.S.Y. O saber de Enf ermagem e sua dimensão na prática. São Paulo, Cortez, 1986. 128 p.

2. BREILH, J. \& GRANDA, E. Investigação da saúde na sociedade: guia pedagógico sobre um novo enfoque do método epidemiológico. São Paulo, Instituto de Saúde/ABRASCO, 1986.

3. CHEPTULIN, A. A dialética materialista. Categorias e leis da dialética. São Paulo. Alfa-Ômega, 1982. p. 20)3-16; 286-328.

4. HAHN, E. \& KOSING, A. A filosofia marxista leninista: curso básico. Lisboa, Avante, 1983.

5. LANE, S.T.M. Consciência/alienação: a ideologia no nível individual. In: LANE, S.T.M. \& CODO, W. (org.) Psicologia social: o homem em movimento. São Paulo, Brasiliense, 1984. p. 40-7. 
6. LAURELL, A.C. A saúde-doença como processo social. In: NU NES E.D. (org.) Medicina social: aspectos históricos e teóricos. São Paulo, Global, 1983. p. 133-58.

7. LIMA, M.L.F. et alii. O enfermeiro e seu compromisso social. In: CONGRESSO BRASILEIRO DE ENFERMAGEM, 31, Fortaleza, 1979. Anais... Brasília, ABEn, 1979.
8. NAKAMAE, D.D. Bases para o encaminhamento da questão do ensino da Enfermagem. São Paulo, Escola de Enfermagem da USP, 1986. Tese dout.

9. SILVA, G.B. da Enfermagem profissional: análise crítica. São Paulo, Cortez, 1986. 143 p. 